\title{
Heparin-Induced Thrombocytopenia (HIT): A Case Study
}

\author{
Catherine E Newkirk
}

\begin{abstract}
Heparin-induced thrombocytopenia (HIT) ranges from an asymptomatic reaction to heparin with a transient mild thrombocytopenia (HIT I) to a life- and limb-threatening immunological reaction, heparin-induced thrombocytopenia with thrombosis (HITT or HIT II). HITT can occur in patients with any heparin exposure and must be recognized and treated quickly and appropriately to prevent symptomatic and/or fatal thrombosis. HIT will be discussed using a case study approach.
\end{abstract}

\begin{abstract}
ABBREVIATIONS: APTT $=$ activated partial thromboplastin time; $\mathrm{AT}=$ anti-thrombin; ${ }^{14} \mathrm{C}=$ carbon-14; CT = computerized topography; $\mathrm{DTI}=$ direct thrombin inhibitor; $F_{c}=$ fragment crystallizable; FDA $=$ Food and Drug Administration; HIPA = heparin-induced platelet aggregation; HIT = heparininduced thrombocytopenia; HITT = heparin-induced thrombocytopenia with thrombosis; $\operatorname{IgG}=$ immunoglobulin G; INR = international normalized ratio; $\mathrm{IU} / \mathrm{ml}=$ international units per milliliter; $\mathrm{IV}=$ intravenous; LMWH = low-molecular-weight heparin; PF4 = platelet factor 4; $\mathrm{RBC}=$ red blood cell; $\mathrm{SC}=$ subcutaneous; $\mathrm{SRA}=$ serotonin release assay; $\mathrm{UFH}=$ unfractionated heparin.
\end{abstract}

The peer-reviewed Clinical Practice Section seeks to publish case studies, reports, and articles that are immediately useful, are of a practical nature, or contain information that could lead to improvement in the quality of the clinical laboratory's contribution to patient care, including brief reviews of books, computer programs, audiovisual materials, or other materials of interest to readers. Direct all inquiries to Libby Spence, $P h D$, CLS(NCA), Clin Lab Sci Clinical Practice Editor, University of Mississippi Medical Center, 2500 North State Street, Jackson, MS 39216, lspence@gme. umsmed.edu.
INDEX TERMS: argatroban, heparin, lepirudin, thrombocytopenia, thrombosis.

Clin Lab Sci 2010;23(1):5

Catherine E. Newkirk, MS, MT(ASCP) is an associate professor, Department of Medical Laboratory Sciences (Hematology), Marist College Poughkeepsie, NY

Address for Correspondence: Catherine E. Newkirk, Department of Medical Laboratory Sciences, Donnelly Hall, Room 109, Marist College, 3399 North Road, Poughkeepsie, NY 12601, (845) 575-3000, ext. 2496, Fax: (845) 575-3184, Email: Catherine.Newkirk@ marist.edu.

\section{INTRODUCTION}

The use of heparin to treat and prevent thromboembolic disorders is well established. Heparin, however, is also associated with heparin-induced thrombocytopenia (HIT), a potentially life- and limbthreatening immunological reaction. If recognized early and treated appropriately, the risks of HIT-associated thrombotic complications can be significantly reduced.

\section{CASE HISTORY}

A 70-year-old male in good health arrived in his local Emergency Room with a table saw injury to his right hand resulting in a near complete amputation of his right thumb and laceration of his middle finger. He was immediately transferred to the regional medical center where an attempt was made to reattach and revascularize the thumb. He was given a bolus injection of heparin intraoperatively and an intravenous infusion of heparin preoperatively and postoperatively. On day 8 , he was sent home. On day 18, he had a follow-up visit with the surgeon. Finding the thumb showing signs of failure, he was scheduled for surgery. The patient complained of pain in his left leg with increasing 


\section{CLINICAL PRACTICE}

intensity over the past week. The surgeon ordered Xrays of the lateral spine which showed advanced degenerative arthritis. Prior to surgery, the whole blood platelet count was $135 \times 10^{9} /$ liter, (reference range: 160 $410 \times 10^{9} /$ liter). This platelet count, performed on day 19, was the first recorded measurement of platelets for this patient. Partial amputation of the right thumb, due to poor vascular supply, was performed on day 20. On day 26, he complained that the pain in his left leg was getting progressively worse and his right heel was tender. His physician noted arthritis, spur and/or gout and ordered Celebrex and Hydrocodon. His platelets were $108 \times 10^{9} /$ liter. Two days later, he was admitted to his local hospital with a pulseless, cyanotic left leg. An angiogram revealed an embolism in his left superficial femoral artery. The next day, an embolectomy was performed to attempt revascularization. The arteries, described as appearing "full of sand", were irrigated with a heparin solution and 48 hour Fragmin therapy was initiated (Fragmin, given by subcutaneous injecttion, is a low-molecular-weight-heparin.). Platelets were measured at $70 \times 10^{9} /$ liter. The patient was transfused with 6 units of platelets and 2 units of packed red blood cells. On day 31, amputation of his left leg below the knee was performed due to a failed revascularization attempt. Platelets were $121 \times 10^{9} /$ liter. Heparin was continued during debridement, revising and closing the stump. On day 48, the patient was discharged to a rehabilitation hospital where an exam on admission revealed an extremely swollen left leg and thigh. An ultrasound revealed acute venous thrombosis and the patient was transferred to the vascular service where IV heparin was started. On day 51, platelets had decreased to $32 \times 10^{9} /$ liter and the patient exhibited diaphoresis, chest pain and shortness of breath. On day 52, the patient had an abrupt onset of slurred speech with weakness in the left upper and lower extremity. A CT scan of his brain revealed a blocked right middle cerebral artery and an electrocardiogram showed acute anterior wall transmural infarction. A CT scan of his lungs demonstrated pulmonary edema. His platelets measured 41 x 10\%/liter. Neurology, hematology, pulmonary and cardiology consults were called in and the first suggestion of heparin-induced thrombocytopenia with thrombosis (HITT) was made. Heparin was discontinued and an emergency order for Hirudin from the regional medical center was placed. On day 53, a repeat CT scan of the brain showed marked edema, infarction of the right internal carotid artery and the right middle cerebral artery, brain stem herniation, herniation of the right frontal lobe, and dilation of the left lateral ventricle. The prognosis was listed as "abysmal" and the patient expired that afternoon. His presumed cause of death was listed as "White Clot Syndrome" secondary to Fragmin and heparin therapy with multiple thromboses.

\section{HEPARIN OVERVIEW}

Heparin, discovered over 80 years ago by McClean, is a heterogeneous mix of glycosaminoglycans with antithrombotic properties. It requires a plasma cofactor, anti-thrombin (AT). Heparin binds to AT causing a conformational change that results in its activation and this activated AT inactivates coagulation factors IIa, Xa, IXa, XIa, and XIIa (IIa and Xa are most sensitive). ${ }^{1}$

Heparin use is well established in the U.S. to treat and prevent thromboembolic disorders. One trillion units are used annually. Heparin has proven efficacy, rapid onset of action, ease of monitoring with the APTT, rapid neutralization with protamine and low cost. ${ }^{1,2,3}$

Two forms of heparin are commonly used (Table 1). Unfractionated heparin (UFH) is a purified preparation of glycosaminoglycans derived from beef lung or pork intestine. UFH is composed of a large number of related compounds with molecular weights from 1,000 to greater than $40,000 .{ }^{4,5,6} \mathrm{UFH}$ non-specifically binds to plasma proteins, macrophages, and endothelial cells, among other things, and thus must be monitored with the APTT to find out how much is acting as an anticoagulant. Low-molecular-weight heparin (LMWH) is derived from UFH by chemical or enzymatic depolymerization. LMWH has a molecular weight range from 2,000-9,000 and has a reduced ability to inactivate thrombin because inactivating thrombin is chain length dependent. LMWH does not need to be monitored because it lacks non-specific binding and, therefore, has excellent bioavailability and predictable distribution. Both UFH and LMWH are cleared by the kidney. ${ }^{1,3}$ 
Table 1. Comparison of Two Forms of Heparin

\begin{tabular}{|c|c|}
\hline$\underline{\mathrm{UFH}}$ & $\underline{\mathrm{LMWH}}$ \\
\hline Inexpensive $^{7}$ & Expensive $^{7}$ \\
\hline Non-specific binding & Lacks non-specific binding \\
\hline Binds PF $4^{6}$ & Less efficient binding of PF $4^{6}$ \\
\hline $1 / 2$ life $-60 \min \left(\mathrm{IV}\right.$, longer SC) ${ }^{1}$ & $1 / 2$ life $3-6$ hours $(S C)^{1}$ \\
\hline Neutralized by protamine ${ }^{1,3,5}$ & $\begin{array}{l}\text { Not fully normalized by } \\
\text { protamine }^{1}\end{array}$ \\
\hline Monitor with APTT & No need to monitor \\
\hline HIT (porcine mucosa) $4.8 \%^{11}$ & HIT (enoxaparin) $0.6 \%{ }^{11}$ \\
\hline HIT with thrombosis $3.3-3.6 \%{ }^{11}$ & $\begin{array}{l}\text { HIT with thrombosis } 0.3- \\
0.6 \%{ }^{11}\end{array}$ \\
\hline MW range $1,000->40,000$ & MW range $2,000-9,000$ \\
\hline Anti-Xa/Anti-IIa ratio $1: 1^{1}$ & Anti Xa/Anti-IIa ratio $2: 1$ to $4: 1$ \\
\hline
\end{tabular}

\section{HEPARIN INDUCED THROMBOCYTOPENIA (HIT) OVERVIEW}

HIT I appears to be a benign reaction to heparin beginning 1-4 days into therapy with a transient mild thrombocytopenia $\left(100-150 \times 10^{9}\right.$ platelets per liter) that is not immune mediated. HIT I is not associated with thrombosis and the patient is asymptomatic. HIT I is manifested in $10-20 \%$ of patients treated with IV heparin. ${ }^{4}$

HIT II, on the other hand, is found in $0.5-5 \%$ of patients on IV heparin, 5-10 days into therapy ${ }^{6,7,8}$ (a distinguishing factor from HIT I); but can occur with any heparin exposure (heparin flushes, heparin coated catheters, etc.). ${ }^{2,9}$ Platelet counts are less than $100 \mathrm{x}$ $10 \%$ liter or have a $30-50 \%$ decrease from baseline. ${ }^{2,4,10}$ Thirty to seventy-five per cent of patients with HIT II have thrombosis which can manifest as deep vein thrombosis, pulmonary embolism, skin necrosis, limb

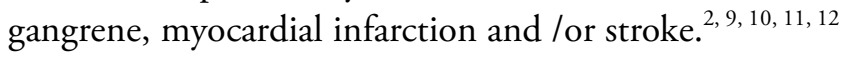
There is a $20 \%$ mortality rate with an additional $10 \%$ amputations and/or major morbidity. ${ }^{6}$ HIT II is immune mediated and heparin must be stopped immediately with administration of alternative anticoagulation. , 4, 6, $13^{2}$

HIT II was first described as "White Clot Syndrome" in
1958 by Weismann and Tobin. It was found in 10 patients on heparin; six of whom died. They described pale salmon-colored clots, rich in platelets. White Clot Syndrome is a misnomer because platelet-rich clots are uncommon in HIT II, in which the majority of clots are RBC-rich fibrin clots. ${ }^{5}$

HIT II has three classifications: isolated HIT with thrombocytopenia only, yet substantial risk of symptomatic and fatal thrombosis; HITT with thrombocytopenia and thrombosis; and rapid onset HIT with thrombocytopenia within 24-48 hours of heparin administration. Rapid onset HIT is associated with recent heparin exposure (within the past 100-120 days). It is not an anamnestic immune response but due to already circulating HIT antibodies. ${ }^{11,14,15}$

\section{HIT MECHANISM OF ACTION}

Alpha granules in activated platelets release PF4 which binds to other platelets activating them. ${ }^{5}$ Heparin binds to PF4 and causes a conformational change in the PF4 protein, "bundling" 4 or 8 molecules. 5 An antibody (90\% IgG) recognizes this PF4-heparin complex as an antigen and forms immune complexes with it. ${ }^{5,8,10,13}$ This antibody activates platelets through $\mathrm{Fc}_{\mathrm{c}}$ receptors on the same or adjacent platelets. 5, 8, 13, 14, 16, 17 This activation causes the release of more PF 4 and prothrombotic microparticles with resultant thrombin generation and fibrin clot formation. ${ }^{5,10,15}$ In addition, these antibodies can bind to Fc receptors on monocytes and endothelial cells, activating them to produce tissue factor, further stimulating thrombosis. ${ }^{4,8,14,17,18}$

HIT II is more commonly associated with UFH of bovine lung or porcine mucosa origin, showing up in 1$5 \%$ of recipients. ${ }^{5,6,7}$ HIT II can also develop with LMWH in $0.2-0.8 \%$ of recipients. ${ }^{4,6}$ Bovine lung UFH has a greater incidence of HIT II than porcine mucosal UFH and porcine mucosal UFH HIT II shows up more frequently than with LMWH. ${ }^{11}{ }^{19}$ This appears to be because heparin chains larger than 12 saccharide units are required to form antigenic PF4-heparin complexes and greater polysaccharide chain lengths are thought to cause increased immunogenicity. ${ }^{6,17}$ 


\section{CLINICAL PRACTICE}

\section{PATIENT MONITORING/TREATMENT}

Patients on heparin should have their platelets monitored, with a baseline count followed by counts every other day between days 4-14 or until the heparin is stopped, whichever occurs first. ${ }^{11,14,20}$ HIT should be suspected if platelets are decreased between days 4-14 of exposure to heparin (less than $100 \times 10^{9} /$ liter or a 30 $50 \%$ decrease below baseline) or if there are any clinical signs or symptoms of a thrombus. ${ }^{2,4,8}$ To assess a pretest probability of HIT, a clinical scoring system known as the " 4 Ts" can be utilized (Table 2). ${ }^{10}$

If HIT is suspected, all forms of heparin must be stopped immediately without waiting for further laboratory testing. ${ }^{2,5,8,10,21}$ Heparin cessation alone, however, does not reduce thrombosis or death because thrombin is still being generated. ${ }^{2}$, 5, 10, 17 A direct thrombin inhibitor (DTI) must be administered for a minimum of 7 days. ${ }^{2,5,8}$ LMWH should not be used because it shows complete cross reactivity with HIT antibodies. $^{2,}$ 7, 15, 17, 22 The DTI should be continued until platelets return to normal ${ }^{14}$ and reach a stable plateau, ${ }^{11}$ at which time it is safe to administer warfarin (an oral Vitamin K antagonist). ${ }^{12}$ The DTI should not be stopped until there are at least five days of overlap with warfarin administration and until the International Normalized Ratio (INR) is in therapeutic range for at least 2 days to assure the warfarin is working to prevent thrombin generation. ${ }^{2,10,12}$ Overlapping treatments is

Table 2. Clinical Scoring System for HIT: the $4 \mathrm{Ts}^{10,14,17}$

$\underline{4 T s}$

Thrombocytopenia:

Decrease

Nadir

Timing of platelet count decrease:

No recent heparin

(within 100 days)

Clear onset between days $5-10$

Recent heparin

$$
\begin{gathered}
\leq 1 \text { day } \\
\text { (prior heparin } \\
\text { exposure within } \\
30 \text { days) }
\end{gathered}
$$$$
\text { or }
$$

\section{Thrombosis or other sequelae}

$$
\begin{aligned}
& \text { New thrombosis } \\
& \text { (confirmed); skin } \\
& \text { necrosis at heparin } \\
& \text { injection site; acute } \\
& \text { systemic reaction } \\
& \text { post-IV UFH bolus }
\end{aligned}
$$

Other causes for Thrombocytopenia
None apparent

\section{Point}

\section{$\underline{0}$ Points}

$<30 \%$

or $<10 \times 10^{9} / \mathrm{L}$

$10-19 \times 10^{9} / \mathrm{L}$

$\leq 4$ days

Onset between days

5 - 10 but unclear

history (e.g. missing

platelet counts) or

$>10$ days

or

$\leq 1$ day

(prior heparin

exposure 30 - 100

days ago)

\footnotetext{
Progressive (increase

in size) or recurrent thrombosis;

erythematous skin

lesions at heparin

injection site; suspected thrombosis (not proven)
} 


\section{CLINICAL PRACTICE}

necessary because warfarin needs 4-5 days for effect and causes decreased Protein $\mathrm{C}$ and $\mathrm{S}$ (natural anticoagulants) before it decreases Vitamin $\mathrm{K}$ dependent coagulation factors (II, VII, IX and X), resulting in persistent thrombin generation linked to limb gangrene and blistering skin due to clots in the microvasculature. ${ }^{2,5,8,11,14}$. The risk for thrombosis in HIT II persists for at least 6 weeks so warfarin treatment is recommended to be continued for a minimum of 2-3 months. ${ }^{15}$ Infusion of platelets is contraindicated while the mechanism activating platelets persists due to possible resultant increased coagulation $^{2}$ (though a recent retrospective study finds no evidence to withhold platelet transfusions, if clinically indicated ${ }^{21}$ ).

If there is a history of heparin use within the past 100 120 days and heparin is newly administered, the patient should be monitored for rapid onset HIT where the platelets decrease within hours. ${ }^{11,15}$ It is recommended that a baseline platelet count be performed and repeated within 24 hours to catch this rapid decrease in platelets due to antibodies formed with the earlier heparin that are still in the circulation. ${ }^{10,11,14}$

\section{DIRECT THROMBIN INHIBITORS (DTIs)}

Direct thrombin inhibitors are key in the treatment of HIT because thrombin plays a central role in HIT. Activated platelets activate the coagulation sequence which generates thrombin. Thrombin enzyme activity depends on two domains: an active catalytic site and an anion binding exosite for fibrin recognition. Individual DTIs act differently on these sites. There are presently two DTIs approved by the FDA for the treatment of HIT: Lepirudin and Argatroban. ${ }^{2}$

Lepirudin is a recombinant form of Hirudin, an anticoagulant extracted from leeches. ${ }^{5,15}$ Lepirudin was the first DTI approved by the FDA for HIT in $1998 .^{2}$ Lepirudin is a bivalent inhibitor, binding both the catalytic site and the exosite of thrombin. ${ }^{2}$ In addition, Lepirudin inhibits both clot-bound and soluble thrombin, thus acting on existing and new thromboses and has no cross-reactivity with HIT antibodies; ${ }^{2,} 17$ although anti-hirudin antibodies are common (up to $84 \%$ of patients) and prevent repeated use. ${ }^{5,11,15}$

Argatroban is an arginine based synthetic thrombin inhibitor approved by the FDA in 2000 for the treatment of $\mathrm{HIT}^{2,}{ }^{2,15}$ It is a monovalent inhibitor which only binds the active catalytic site on thrombin so it is not as effective as Lepirudin. ${ }^{2}$ It inhibits clotbound and soluble thrombin; and has no cross reactivity with HIT antibodies. ${ }^{2}$ The high cost of both DTIs is minimal compared to the cost of major complications associated with HIT. ${ }^{2}$

\section{LABORATORY TESTING}

Laboratory testing includes temporal platelet counts, functional assays for serotonin release, heparin induced platelet aggregation, platelet aggregation, flow cytometry for activated platelet markers, and antibody detection with enzyme immunoassay.

Routine temporal platelet counts (a baseline and at least every other day between days 4-14) are more important than other studies. ${ }^{11}$ Platelets decrease before antibody titers rise and there is a high risk of thrombosis with a decreased platelet count (with or without detection of HIT antibodies). ${ }^{9}, 11$ Testing for antibodies without clinical indications of thrombosis is not useful. ${ }^{11}$

The serotonin release assay (SRA) is considered the gold standard for functional tests. ${ }^{8,17,21,22}$ Platelets from normal donors are labeled with radioactive serotonin $\left({ }^{14} \mathrm{C}\right.$ serotonin $)$ and added to different concentrations of heparin representing no heparin, therapeutic levels $(0.1$ to $0.5 \mathrm{IU} / \mathrm{ml}$ ) and an overload ( $\geq 10 \mathrm{IU} / \mathrm{ml}$ ). 5, 8, 17, 22, 23 The overload inhibits binding and yields a negative test to assure that heparin is the culprit. ${ }^{23}$ Serum from a patient suspected of HIT is added and ${ }^{14} \mathrm{C}$ serotonin released by activated platelets is measured by scintillation counter. ${ }^{22,23}$ Positive results are confirmed by suppression with Anti-Fc receptor antibodies to assure that this is the site of activation. ${ }^{21,22}$ This assay is moderately-highly sensitive (a sufficiently high titer of antibodies is needed to activate platelets) and highly specific. ${ }^{2,21}$ 


\section{CLINICAL PRACTICE}

Heparin induced platelet aggregation (HIPA) involves combining washed platelets from healthy donors with sera from patients suspected of HIT and different concentrations of heparin (no heparin, therapeutic levels and an overload) in microtiter plates. ${ }^{8,} 22$ If positive, platelets should fall out of solution as indicated by transparency on a microtiter plate. ${ }^{22}$

Platelet aggregation, using platelet-rich plasma from healthy donors incubated with patient sera and known concentrations of heparin, is moderately-highly sensitive and highly specific. ${ }^{2,8,22}$ Aggregation is considered positive by a sharp slope ( $\geq 20 \%$ per minute ) and maximum aggregation of $\geq 50 \%$ within 20 minutes. ${ }^{22}$

An emerging method involving flow cytometry also uses platelets from healthy donors, different concentrations of heparin and sera from patients suspected of HIT. ${ }^{22} \mathrm{~A}$ monoclonal antibody labeled with a fluorescent tag to a platelet activation marker (such as the generation of microparticles) on the platelet surface is utilized. ., $^{22}$ Binding of the antibody reflects activation of platelets and is analyzed by flow cytometry. ${ }^{22}$

Enzyme-linked immunoassay methods utilize a microtiter plate coated with PF4 and heparin. ${ }^{9,22}$ Serum from a patient suspected of HIT is added, followed by anti-human IgG antibody with alkaline phosphatase and a chromogen tag., 22 Change in absorbance corresponds to the presence of antibodies to the heparin-PF 4 complex ${ }^{2,9,22}$ but does not demonstrate the ability of the antibody to activate platelets. ${ }^{14}$ Currently, the FDA requires reporting as positive or negative, ${ }^{24}$ but higher antibody titers are associated with the development of thrombotic complications. ${ }^{13,24}$ This method is ex-tremely sensitive but only moderately specific. $^{2,9,15,17,24}$

When testing for HIT antibodies, an enzyme immunoassay should be performed first because it is extremely sensitive and, if negative, rules out HIT. ${ }^{2,8,10}$, ${ }^{13,21}$ If positive, it should be followed with the serotonin release assay which is highly specific for the HIT antibody. $2,8,21,25$
HIT treatment, however, should be initiated upon clinical suspicion and not await laboratory testing confirmation ${ }^{12,14,17}$ because the potential is great for life- and limb-threatening complications.

\section{CASE SUMMARY}

This patient had a classic case of heparin-induced thrombocytopenia with thromboses, which escaped diagnosis at three different medical facilities and under the care of numerous doctors. He had his first exposure to heparin with emergency surgery to reattach his thumb. No baseline measurement of platelets was recorded at that time. He underwent a second surgery, with more heparin and his first platelet count, recorded on day 19 , was $135 \times 10^{9} /$ liter (reference range: 160$410 \times 10^{9} /$ liter). Without a baseline for comparison, it is impossible to know if this represented a significant decrease in platelets. Over the next few weeks, platelets continued to decrease; more heparin was administered; an embolectomy was attempted; and Fragmin therapy followed. Fragmin is a LMWH that has high cross reactivity with HIT II antibodies. Platelets continued to fall and the patient was transfused with 6 units of platelets, possibly adding fuel to the fire. After amputation of his left leg below the knee with more heparin administered, platelets were recorded at $121 \mathrm{x}$ $10^{9} /$ liter, probably increased due to the transfusions. Following discharge to a rehabilitation hospital, a heparin IV was started to treat acute venous thrombosis. Platelets continued to decrease and were recorded at 32 x $10^{9} /$ liter when the patient developed signs of stroke, myocardial infarction and pulmonary edema. A neurologist and hematologist, called in for consult, made the first suggestion of HITT. Heparin was discontinued and an emergency order of Hirudin was placed. Hirudin is an anti-coagulant extracted from leeches with anti-thrombin activity and low cross reactivity with HIT II antibodies. The diagnosis of HITT was considered much too late and the patient expired (53 days after the first heparin dose) before the Hirudin arrived.

Death of this patient could possibly have been avoided had a baseline platelet count been performed before the first heparin administration, with temporal platelet 


\section{CLINICAL PRACTICE}

counts performed every other day on days 4-14 following. A baseline platelet count is important in order to recognize a significant decrease in platelets and alert the physician to the possibility of HIT II. If HIT II was suspected early, all heparin could have been discontinued and a direct thrombin inhibitor administered with a transition to warfarin and continued anticoagulation therapy for 2-3 months. The patient's outcome could have been decidedly better.

Clin Lab Sci encourages readers to respond with thoughts, questions, or comments regarding this article. Email responses to westminsterpublishers@comcast.net. In the subject line, please type "CLIN LAB SCI 23(1) RE NEWKIRK". Selected responses will appear in the Dialogue and Discussion section in a future issue. Responses may be edited for length and clarity. We look forward to hearing from you.

\section{REFERENCES}

1. Hirsh J, Raschke R. Heparin and low-molecular-weight heparin. CHEST. 2004 Sept; 126(Suppl 3): 188S-203S.

2. Spinler SA, Dager W. Overview of heparin-induced thrombocytopenia. Am J Health-Syst Pharm. 2003 Oct 15; 60(Suppl 5): S5-S11.

3. Bussey H. Traditional anticoagulant therapy: why abandon half a century of success? Am J Health-Syst Pharm. 2002 Oct 15; 59(Suppl 6): S3-S6.

4. King JE. Does my patient have heparin-induced thrombocytopenia? Nursing. 2003 Nov; 33(11): 24.

5. Kelton JG. The pathophysiology of heparin-induced thrombocytopenia. CHEST. 2005 Feb; 127(Suppl 2): 9S-20S.

6. Rauova L, Poncz M, McKensie SE, Reilly MP, Arepally G, and others. Ultralarge complexes of PF4 and heparin are central to the pathogenesis of heparin-induced thrombocytopenia. Blood. 2005 Jan 1; 105(1): 131-8.

7. Warkentin TE, Levine MN, Hirsh J, Horsewood P, Roberts RS, and others. Heparin-induced thrombocytopenia in patients with low-molecular-weight heparin or unfractionated heparin. N Engl J Med. 1995 May 18; 332(20): 1330-6.

8. Chong $\mathrm{BH}$, Isaacs A. Heparin-induced thrombocytopenia: what clinicians need to know. Thromb Haemost 2009 Feb; 101(2): 279-83.

9. Refaai MA, Laposata M, Van Cott EM. Clinical significance of a borderline titer in a negative ELISA test for heparin-induced thrombocytopenia. Am J Clin Pathol. 2003; 119: 61-5.
10. Selleng K, Selleng S, Greinacher A. Heparin-induced thrombocytopenia in intensive care patients. Semin. Thromb. Hemost. 2008; 34(5): 425-38.

11. Warkintin TE, Greinacher A, Koster A, Lincoff AM. Treatment and prevention of heparin-induced thrombocytopenia, American College of Chest Physicians evidenced-based clinical practice guidelines ( $8^{\text {th }}$ edition). CHEST 2008 June; 133(Suppl): 340S-80S.

12. Abdel-Wahab OI, Rosovsky RP, Warth JA. Warfarin-induced skin necrosis in a patient with heparin-induced thrombocytopenia: two diseases or one? Acta Haematol. 2008; 120: $117-22$.

13. Warkentin TE, Sheppard JI, Moore JC, Cook RJ, Kelton JG. Studies of the immune response in heparin-induced thrombocytopenia. Blood. Epub 2009 Jan 14.

14. Hassell K. Heparin-induced thrombocytopenia: diagnosis and management. Thromb Res. 2008; 123 Suppl: S16-S21.

15. Alving B. How I treat heparin-induced thrombocytopenia and thrombosis. Blood. 2003 Jan 1; 101(1): 31-7.

16. Krauel K, Fürll B, Warkentin TE, Weitschies W, Kohlmann T, and others. Heparin-induced thrombocytopenia - therapeutic concentrations of danaparoid, unlike fondaparinux and direct thrombin inhibitors, inhibit formation of platelet factor 4heparin complexes. J Thromb Haemost. 2008; 6:2160-7.

17. Gruel Y, Pouplard C. Overview of heparin-induced thrombocytopenia. Diagnosis and treatment in Europe with an emphasis on France. Semin Thromb Hemost. 2008; 34(Suppl 1): 27-36.

18. Vissac AM, Amiral J. Mechanisms involved in heparin-induced thrombocytopenia and associated thrombosis. Semin Thromb Hemost. 2008; 34(Suppl 1): 18-26.

19. Rosove $\mathrm{MH}$. New insights in heparin-induced thrombocytopenia. Blood. 2005 Jan 1; 105(1): 4-5.

20. Warkentin TE. Heparin-induced thrombocytopenia in medical patients. Blood. 2003 April 15; 101(8): 2903.

21. Hopkins CK, Goldfinger D. Platelet transfusions in heparininduced thrombocytopenia: a report of four cases and review of literature. Transfusion. 2008 Oct; 48: 2128-32.

22. Savi P, Chong BH, Greinacher A, Gruel Y, Kelton JG, and others. Effect of fondaparinux on platelet activation in the presence of heparin-dependent antibodies: a blinded comparative multicenter study with unfractionated heparin. Blood. 2005 Jan 1; 105 (1): 139-44.

23. Sheridan D, Carter C, Kelton JG. A diagnostic test for heparininduced thrombocytopenia. Blood. 1986 Jan; 67(1): 27-30.

24. Ban-Hoefen M, Francis C. Heparin induced thrombocytopenia and thrombosis in a tertiary care hospital. Thromb Res. Epub 2009 Feb 3.

25. Kawano H, Toyoda K, Miyata S, Yamamoto H, Okamoto A, and others. Heparin-induced thrombocytopenia: a serious complication of heparin therapy for acute stroke. Cerebrovasc Dis. 2008; 26 641-9. 